\title{
The Effect of Seed Size on Seed Recovery and Quality in Chickpea (Cicer arietinum L.)
}

\author{
Ashok S. Sajjan ${ }^{1}$, A.K. Guggari²
}

10.18805/LR-4414

\begin{abstract}
Background: Quality seed is major input in increasing the productivity of agricultural crops. Seed after harvesting contains many undesirable materials and unfit for sowing. If the farmer is to be persuaded to pay for high quality seed, the seed he buys must be undeniably be pure and flow without difficulty through planter or drill. To separate different size seed material, many equipments have been developed which exploit the differences between the physical characteristics of seeds.

Methods: An experiment was conducted to standardize the sieve size for seed grading in chickpea. The freshly harvested seeds of were graded using different sieve sizes. The screens used in this experiment were $7.0 \mathrm{~mm} \mathrm{R}, 6.50 \mathrm{~mm} \mathrm{R}, 6.0 \mathrm{~mm} \mathrm{R}, 5.50 \mathrm{~mm}$ $\mathrm{R}, 4.75 \mathrm{~mm} \mathrm{R}, 3.75 \mathrm{~mm} \mathrm{R}$ and Bulk seeds (control). The seeds which retained over the screen were subjected to seed recovery and quality tests.

Result: The results of the experiment indicated that the seed recovery ranged from 90.4 per cent to 97.82 per cent among the different size grades. As the screen size decreased from 7.0 to $4.75 \mathrm{~mm}$, the per cent seed recovery was increased but seed quality parameters were decreased and well below the Indian Minimum Seed Certification Standard (IMSCS). The positive association of seed size and seed qualities were recorded. The $5.5 \mathrm{~mm}$ sieve recorded $96.4 \%$ seed recovery as compared to $6.0 \mathrm{~mm}$ sieve (94.4\%) and found to be better by considering two per cent higher seed recovery and other higher germination, vigour index although there is recommendation is 4.75 to $6.0 \mathrm{~mm}$ range. Hence, the seed producer is benefitted by higher seed recovery and profit and without compromising minimum seed certification standards.
\end{abstract}

Key words: Chickpea, Seed germination, Seed recovery, Seedling vigour index, Size grading.

\section{INTRODUCTION}

Good quality genetically pure seed of high-yielding varieties is a critical input in crop production for obtaining high yields. Inadequate availability of seed of improved cultivars in food legumes has been a major bottleneck in adoption of improved cultivars by the farmers. In India, chickpea is cultivated almost in all parts of the country mainly as a rainfed crop (68\% area). During 2017-18, chickpea production has been estimated to be about 11.23 million tones, which is $46 \%$ of the total pulses production (23.95 mt) in India. Among chickpea growing states, Madhya Pradesh, Maharashtra, Rajasthan, Uttar Pradesh andhra Pradesh, Karnataka, Chhattisgarh, Bihar and Jharkhand contribute more than $95 \%$ to the total production. In India, both desi and kabuli type chickpea varieties are grown. In recent years, the country has witnessed remarkable increase in area, production and productivity of chickpea (Dixit et al., 2019). Seed size an important parameter will contribute for seed vigour which is manifested through higher plant stand, plant growth and yield. Generally big seeds with higher amount of initial food reserves emerge early and uniformly and grow vigorously in field and exhibit early advantage of plant vigour with respect to plant performance and yielding ability compared to small and medium seeds in several crops (Poma et al., 1990). On the contrary in some crops even medium, small and bulk seeds were also found to have equal beneficial effects as that of big seeds with respect to field performance. The small and medium seeds require less
1Department of Seed Science and Technology, College of Agriculture, University of Agricultural Sciences, Vijaypur-586 101, Karnataka, India. ${ }^{2}$ Department of Agronomy, College of Agriculture, University of Agricultural Sciences, Vijaypur-586 101, Karnataka, India.

Corresponding Author: Ashok S. Sajjan, Department of Seed Science and Technology, College of Agriculture, University of Agricultural Sciences, Vijaypur-586 101, Karnataka, India.

Email: assajjan@gmail.com

How to cite this article: Sajjan, A.S. and Guggari, A.K. (2022). The Effect of Seed Size on Seed Recovery and Quality in Chickpea (Cicer arietinum L.). Legume Research. DOI: 10.18805/LR-4414.

Submitted: 11-05-2020 Accepted: 17-01-2022 Online: 19-02-2022

moisture for germination, emerge early, establish early, grow vigorously and yield equally as that of big seeds (Kurdikeri, 1991). Studies pertaining to seed grading based on seed size in relation to seed quality characters are warranted as amount of food reserve in seed is the basic requirement for its future expression as germination and final establishment at field. In addition to obtain uniform seed size within a variety, size grading is inevitable.

Quality seed is major input in increasing the productivity of agricultural crops. Seed after harvesting contains many undesirable materials like seeds of other crops, weed seeds, immature seeds, damaged seeds, seeds which are too small or too large, plant materials and other inert matters. Some of this material is not positively harmful, but tends to hold moisture and adds to the bulk of material that has to be 
The Effect of Seed Size on Seed Recovery and Quality in Chickpea (Cicer arietinum L.)

handled and supplied. Moreover, if the farmer is to be persuaded to pay for high quality seed, the seed he buys must be undeniably be pure and flow without difficulty through planter or drill. To separate these different kinds of material, many equipments have been developed which exploit the differences between the physical characteristics of the various components of the seed mixture. The most important differences are in size, shape and density. Separations based on these characteristics are made by perforated screens and by modifiable air blasts. The screens are made of sheet metal or of woven wire mesh and the holes may be rectangular, round, or triangular in shape. Seed cleaning usually requires a succession of operations and these can be regarded as proceeding in three stages viz. pre-cleaning, basic cleaning and separation and grading. Therefore, studies were made in chickpea cv. JG-11 to fix optimum sieve size to obtain the required higher seed recovery and seed quality characters for higher planting value. (Anuradha, et al,2009). At present the sieve size of 4.75 to $6.0 \mathrm{~mm}$ has been suggested by Seed Certification Agency to process the chickpea seeds and it is based on old varieties. It is often observed that the seed growers are losing considerable quantity of good seed which is treated as a rejection and economically loss. Hence, the present research on the effect of seed size on seed recovery and quality in Chickpea was undertaken.

\section{MATERIALS AND METHODS}

Freshly harvested chickpea bulk seed lots of JG-11 produced at College of Agriculture, Vijayapur, Karnataka was used for size grading. The seeds were graded using different sieve sizes The screens used in this experiment were $7.0 \mathrm{~mm}$ $\mathrm{R}, 6.50 \mathrm{~mm} \mathrm{R}, 6.0 \mathrm{~mm} \mathrm{R}, 5.50 \mathrm{~mm} \mathrm{R}, 4.75 \mathrm{~mm} \mathrm{R}, 3.75 \mathrm{~mm}$ $R$ and Bulk seeds (Control). The seeds which retained over the screen were subjected to seed quality tests. Seed recovery was calculated by using following formula and was expressed in per cent $(\%)$

Seed recovery $(\%)=$

$\frac{\text { Weight of seeds retained on sieves }}{\text { Weight of bulk seeds }} \times 100$
The hundred seed weight in grams $(\mathrm{g})$ was recorded from each treatment as per the procedure given by ISTA (Anonymous, 2013). Seed germination test was conducted using four replicates of 100 seeds each in the paper (between paper) medium and incubated in the seed germination room maintained at $25 \pm 1^{\circ} \mathrm{C}$ temperature and $90 \pm 5 \%$ relative humidity. The number of normal seedlings in each replication was counted at the end of eight days and the mean germination percentage (\%) was calculated (Anonymous, 2013). The seedling vigour index was calculated by using the formula:

Seedling vigour index $=$

Germination $(\%) \times$ Total seedling length $(\mathrm{cm})$

As suggested by Abdul-Baki and Anderson (1973).

Field emergence was estimated by sowing 100 seeds in 4 replications in the field. Observations were recorded on $14^{\text {th }}$ day after sowing. The average field emergence was expressed as percentage of seedling emerged. The experiment was carried out in complete randomized design. Seed quality parameters were evaluated at Department of Seed Science and Technology, College of Agriculture, Vijayapur, University of Agricultural Sciences, Dharwad, Karnataka, India for two years during 2017 and 2018. The results were subjected to pooled analysis of variance and tested for significance according to Gomez and Gomez (2010). Further large scale trial $5.50 \mathrm{~mm}$ versus $5.0 \mathrm{~mm}$ was carried out at various seed unit viz. Seed Unit, Vijayapur, Dharwad, Raichur, Bidar, ARS, Kalaburgi and ARS, Bhimarayangudi for confirmation of the results and final recommendation.

\section{RESULTS AND DISCUSSION}

Seed grading is an integral part of seed production for enhanced planting value. In addition to obtain uniform seed size within a variety, size grading is essential. The results of the pooled analysis was significantly differed the Seed recovery and physical purity due to size grading in Chickpea (Table 1). The seed recovery ranged from 90.4 per cent to 97.82 per cent among the different size grades. As the screen size decreased from 7.0 to $4.75 \mathrm{~mm}$, the per cent

Table 1: Seed recovery and physical purity as influenced by size grading in chickpea.

\begin{tabular}{|c|c|c|c|c|c|c|}
\hline \multirow{2}{*}{$\begin{array}{l}\text { Sieve size } \\
\text { in }(\mathrm{mm})\end{array}$} & \multicolumn{3}{|c|}{ Seed recovery (\%) } & \multicolumn{3}{|c|}{ Physical purity (\%) } \\
\hline & 2017 & 2018 & Pooled mean & 2017 & 2018 & Pooled mean \\
\hline 7.0 & 89.3 & 91.6 & 90.4 & 99.6 & 99.3 & 99.5 \\
\hline 6.5 & 95.7 & 92.7 & 94.2 & 99.2 & 99.3 & 99.2 \\
\hline 6.0 & 95.3 & 93.5 & 94.4 & 98.5 & 98.7 & 98.6 \\
\hline 5.5 & 96.6 & 96.2 & 96.4 & 98.6 & 98.4 & 98.5 \\
\hline 4.75 & 98.1 & 97.0 & 97.5 & 98.0 & 98.1 & 98.0 \\
\hline 3.25 & 98.4 & 97.2 & 97.82 & 92.7 & 92.6 & 92.6 \\
\hline Bulk seed & 100.0 & 100.0 & 100.0 & 94.6 & 94.5 & 94.6 \\
\hline Mean & 96.2 & 95.48 & 95.8 & 97.3 & 97.3 & 97.3 \\
\hline Sem \pm & 1.47 & 0.52 & 3.0 & 0.51 & 0.40 & 0.25 \\
\hline CD @ 1\% & 4.49 & 1.60 & 2.26 & 1.58 & 1.23 & 0.76 \\
\hline
\end{tabular}


The Effect of Seed Size on Seed Recovery and Quality in Chickpea (Cicer arietinum L.)

seed recovery was increased (Fig 1). The results are in conformity with the findings of Anuradha et al., (2009) and Ganiger et al., (2016) in green gram. Physical purity exhibited significant difference between different sieve sizes. The highest physical purity percentage was recorded in sieve size $7.0 \mathrm{~mm}(99.5 \%)$ and minimum in bulk seeds. All the graded seeds in different sieve size meets the minimum seed certification standards except $3.25 \mathrm{~mm}$ and bulk seeds indicating size grading is mandatory for planting seeds. The data on test weight and seed germination were significantly influenced by size grading (Table 2 ). The results of the study revealed that seed size had positive association with seed weight, the hundred seed weight observed with different sieve size exhibited a reduction with decrease in size of sieve. The highest hundred seed weight was recorded in $7.0 \mathrm{~mm}(23.9)$ and least in $3.25 \mathrm{~mm}(19.9 \mathrm{~g})$ sieve size seeds. Similarly, significant differences were observed in standard germination test (Fig 1 and Photo 1). The seeds retained on $7.0 \mathrm{~mm}$ sieve recorded highest germination $(98.0 \%)$ and reduced with decrease in sieves size and

Table 2: The test weight and germination as influenced by size grading in chickpea.

\begin{tabular}{|c|c|c|c|c|c|c|}
\hline \multirow{2}{*}{$\begin{array}{l}\text { Sieve size } \\
\text { in }(\mathrm{mm})\end{array}$} & \multicolumn{3}{|c|}{ Test weight (g) } & \multicolumn{3}{|c|}{ Seed germination (\%) } \\
\hline & 2017 & 2018 & Pooled mean & 2017 & 2018 & Pooled mean \\
\hline 7.0 & 22.3 & 25.5 & 23.9 & 98.3 & 97.6 & 98.0 \\
\hline 6.5 & 22.0 & 23.8 & 22.9 & 97.3 & 96.6 & 97.0 \\
\hline 6.0 & 21.9 & 23.3 & 22.6 & 95.6 & 95.0 & 95.3 \\
\hline 5.5 & 19.7 & 23.0 & 21.3 & 95.3 & 94.6 & 95.0 \\
\hline 4.75 & 19.3 & 21.5 & 20.4 & 94.0 & 94.0 & 94.0 \\
\hline 3.25 & 18.9 & 21.0 & 19.9 & 93.3 & 91.3 & 92.3 \\
\hline Bulk seed & 20.9 & 22.1 & 21.5 & 94.0 & 94.3 & 94.1 \\
\hline Mean & 20.6 & 22.9 & 21.9 & 95.4 & 94.8 & 95.1 \\
\hline Sem \pm & 3.6 & 0.85 & 0.40 & 0.96 & 1.01 & 0.36 \\
\hline CD @ 1\% & 1.1 & 2.60 & 1.51 & 2.95 & 3.09 & 1.35 \\
\hline
\end{tabular}

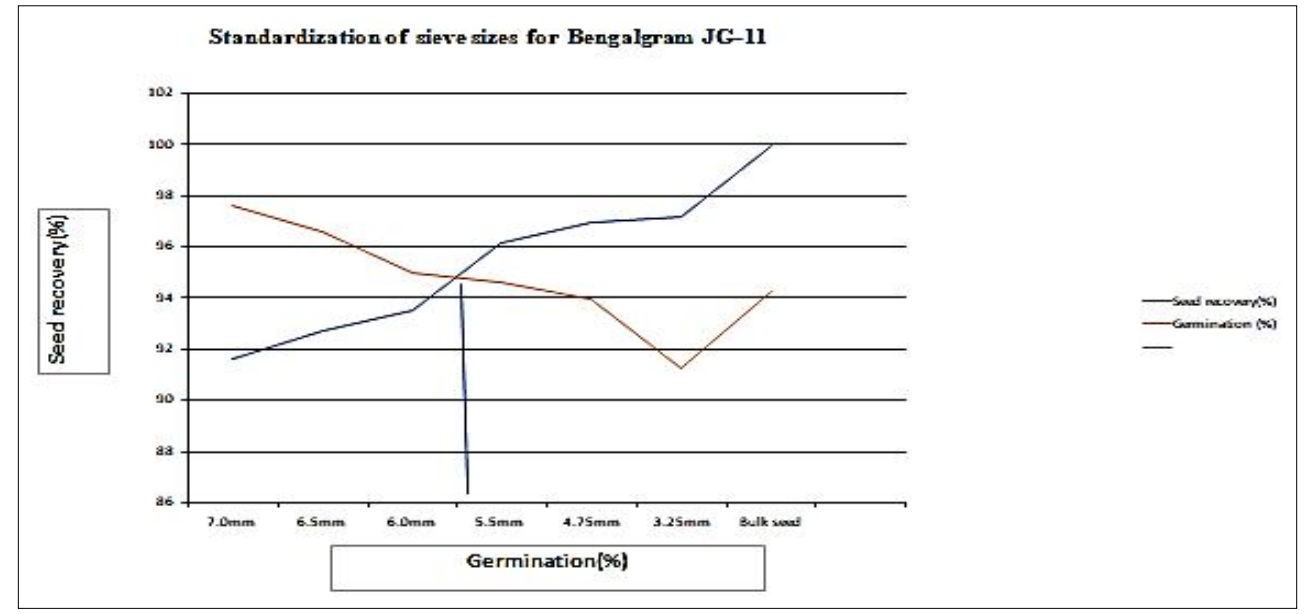

Fig 1: Effect of size grading on Seed recovery and germination as influenced by size grading in chickpea. Seed Germination
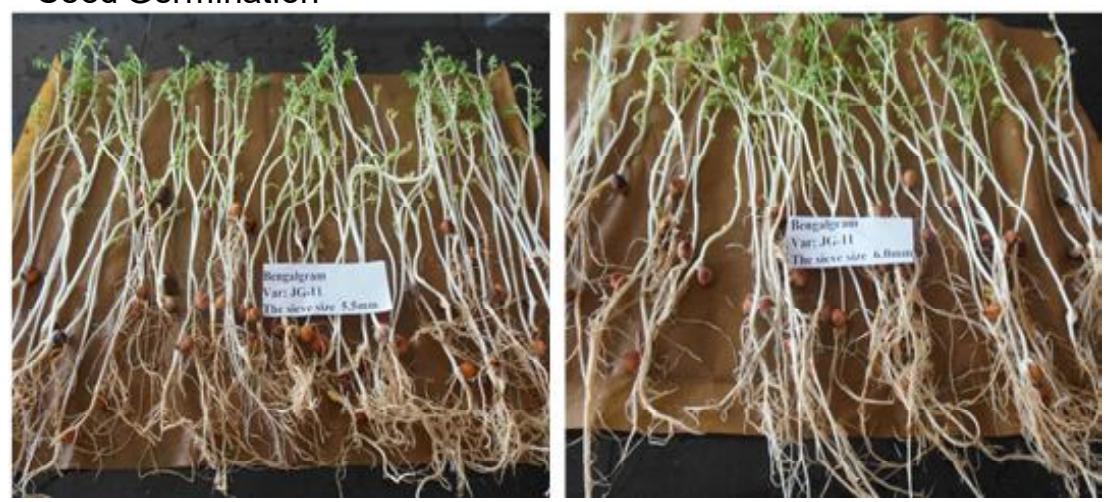

Photo 1: Effect of size grading on germination as influenced by size grading in chickpea. 
The Effect of Seed Size on Seed Recovery and Quality in Chickpea (Cicer aarietinum L.)

Table 3: Seedling vigour index and field emergence as influenced by size grading in chickpea.

\begin{tabular}{|c|c|c|c|c|c|c|}
\hline \multirow{2}{*}{$\begin{array}{l}\text { Sieve size } \\
\text { in }(\mathrm{mm})\end{array}$} & \multicolumn{3}{|c|}{ Seedling vigour index } & \multicolumn{3}{|c|}{ Field emergence (\%) } \\
\hline & 2017 & 2018 & Pooled mean & 2017 & 2018 & Pooled mean \\
\hline 7.0 & 2015 & 2910 & 2462 & 85.6 & 90.6 & 88.1 \\
\hline 6.5 & 1909 & 2599 & 2254 & 85.9 & 89.3 & 87.6 \\
\hline 6.0 & 1848 & 2445 & 2146 & 84.8 & 89.0 & 86.9 \\
\hline 5.5 & 1811 & 2481 & 2146 & 85.0 & 87.7 & 86.3 \\
\hline 4.75 & 1647 & 2351 & 1999 & 62.4 & 70.3 & 66.3 \\
\hline 3.25 & 1644 & 2131 & 1887 & 55.6 & 62.3 & 58.9 \\
\hline Bulk seed & 1886 & 2446 & 2166 & 65.4 & 72.5 & 68.9 \\
\hline Mean & 1601 & 2480 & 2151 & 74.9 & 80.2 & 77.6 \\
\hline Sem \pm & 159.2 & 98.6 & 65.2 & 1.4 & 1.8 & 0.98 \\
\hline CD @ 1\% & 473.9 & 301.4 & N.S. & 4.5 & 4.0 & 2.42 \\
\hline
\end{tabular}

Table 4: Results of large scale Trials conducted for standardization sieve size for grading of chickpea.

\begin{tabular}{|c|c|c|c|c|}
\hline Stations & Treatments & Seed recovery $(\%)$ & Germination (\%) & Vigour index \\
\hline \multirow[t]{2}{*}{ Seed Unit, Vijayapur } & $\mathrm{T} 1-5.50 \mathrm{~mm}(\mathrm{R})$ & 95.8 & 98.0 & 1784 \\
\hline & $\mathrm{T} 2-5.00 \mathrm{~mm}(\mathrm{R})$ & 97.8 & 96.0 & 1349 \\
\hline \multirow[t]{2}{*}{ Seed Unit, Dharwad } & $\mathrm{T} 1-5.50 \mathrm{~mm}(\mathrm{R})$ & 96.6 & 93.0 & 1953 \\
\hline & $\mathrm{T} 2-5.00 \mathrm{~mm}(\mathrm{R})$ & 98.5 & 90.0 & 1620 \\
\hline \multirow[t]{2}{*}{ Seed Unit, Raichur } & $\mathrm{T} 1-5.50 \mathrm{~mm}(\mathrm{R})$ & 93.75 & 97.0 & 1940 \\
\hline & $\mathrm{T} 2-5.00 \mathrm{~mm}(\mathrm{R})$ & 94.0 & 96.0 & 1824 \\
\hline \multirow[t]{2}{*}{ ARS, Kalaburgi } & $\mathrm{T} 1-5.50 \mathrm{~mm}(\mathrm{R})$ & 90.17 & 95.0 & 1710 \\
\hline & $\mathrm{T} 2-5.00 \mathrm{~mm}(\mathrm{R})$ & 93.25 & 90.0 & 1530 \\
\hline \multirow[t]{2}{*}{ Seed Unit, Bidar } & $\mathrm{T} 1-5.50 \mathrm{~mm}(\mathrm{R})$ & 77.4 & 93.0 & 1820 \\
\hline & $\mathrm{T} 2-5.00 \mathrm{~mm}(\mathrm{R})$ & 93.3 & 93.0 & 1627 \\
\hline \multirow[t]{2}{*}{ ARS, B.gudi } & $\mathrm{T} 1-5.50 \mathrm{~mm}(\mathrm{R})$ & 89.0 & 95.0 & 1520 \\
\hline & $\mathrm{T} 2-5.00 \mathrm{~mm}(\mathrm{R})$ & 91.25 & 92.0 & 1377 \\
\hline
\end{tabular}

minimum was seen in $3.25 \mathrm{~mm}$ sieve $(92.3 \%)$, seed germination percentage which is above the minimum seed certification standards (85\%). The higher germination in large seeds may due to higher amount of food reserves and increased activity of redox enzymes in the seeds helping in breaking down the complex food reserves into simple soluble sugars. The positive association of seed size and seed weight was reported by Ganiger et al., (2016) in greengram. Similarly Suma et al., (2014) reported in sesame where in seed size and seed weight was positively related.

Seedling vigour index and field emergence is varied with size grading in Chickpea (Table 3). The The pooled mean Seedling vigour index reduced with decrease in sieve size seedling vigour index was highest in $7.0 \mathrm{~mm} \mathrm{(2462)}$ and least in $3.25 \mathrm{~mm}$ sieve size seeds (1887). Similar trend was also observed in field emergence parameters. Ganiger et al., (2016) in green gram reported that seed size, seed weight and seed quality characters are positively related to each other. Seed quality parameters exhibited a significant reduction with large, medium, smaller sized seeds. This may be due to larger seeds possessed more vigour than smaller seeds due to the presence of more of food material. These results are agreement with findings of Rajesekaran (2001) in niger also noticed that seedling vigour characteristics were positively correlated with seed size and seed weight. The relatively higher vigour associated with larger size could also be ascribed to the more mature embryo containing adequate nutrient reserves both contributing its physiological stamina or vigour factor residing in it (Pollack and Roos, 1972). The $5.5 \mathrm{~mm}$ sieve recorded $96.4 \%$ seed recovery as compared to $6.0 \mathrm{~mm}$ sieve and found to be better by considering higher seed recovery $(2 \%)$ and other higher germination, vigour index although there is recommendation is 4.75 to $6.0 \mathrm{~mm}$ range. Hence, the seed producer is benefitted by higher seed recovery and meeting minimum seed certification standards Therefore, it is concluded that $5.5 \mathrm{~mm}$ sieve may be recommended for processing. Based on favorable results and it is decided to take up large scale trail for confirmation of results. The large scale trails on $5.50 \mathrm{~mm}$ versus $5.0 \mathrm{~mm}$ was carried out at various seed unit viz. Seed Unit, Vijayapur, Dharwad, Raichur, Bidar, ARS, Kalaburgi and ARS, Bhimarayangudi. The similar results were recorded in all the seed units (Table 4).

\section{CONCLUSION}

Finally, the study inferred that, a sieve size of $5.5(R) \mathrm{mm}$ registered higher seed recovery, physical purity, germination, test weight, field emergence and vigour index which is above the minimum seed certification standards. Hence, the 
chickpea CV. JG-11 can be processed using $5.5 \mathrm{~mm}(\mathrm{R})$ grading sieve for better seed recovery and quality. The seed producer is economically benefitted by higher seed recovery without compromising Indian minimum seed certification standards.

\section{Conflict of interest: None.}

\section{REFERENCES}

Abdul-Baki, A.A., Anderson, J.D. (1973). Vigour determination in soybean by multiple criteria. Crop Science. 13: 630-633.

Anonymous. (2013). International Rules for Seed Testing. Seed Science and Technology. 27: 25-30.

Anuradha, R., Balamurugan, P., Srimathi P. and Sumathi, S. 2009, Influence of seed size on seed quality of Chickpea (Cicer arietinum L.), Legume Research. 32(2): 133-135.

Dixit, G.P., Srivastava, A.K. and Singh, N.P. (2019). Marching towards self-sufficiency in Chickpea, Current Science. 116(2): 239-242.

Ganiger, B.S., Basave Gowda, G.Y., Lokesh and Rekha. (2016). Standardization of screen sizes for green gram seed processing. The Bioscan. 11(4): 2379-2381.
Gomez, K.A., Gomezm, A.A. (2010). Statistical Procedures for Agricultural Research. Published by John Wiley and Sons,Inc. U.K.

Kurdikeri, M.B. (1991). Studies on seed quality in hybrid maize (Zea mays L.). PhD Thesis, University of Agricultural Sciences. Bangalore, Karnataka (India).

Pollack, B.M. and E.E. Roos. (1972). Seed Biology I.T.T. Kozlowaski, Academic Press New York. pp. 313-387.

Poma, I., Sarno, R., Noto, F., Zora, D. (1990). Effect of sowing date on yield and quality characteristics of chickpeas. Informatore Agrario. 46(40): 53-55.

Rajasekaran, R. (2001). Seed production, processing and storage studies in niger [Guizotia abyrrinica (L.) f.cass.] cv. Paiyur 1, M.Sc. (Ag.) Thesis, Tamil Nadu Agricultural University, Coimbatore.

Suma, N., Srimathi, P and Sumathi, S. (2014). Influence of size grading on seed and seedling quality characteristics of Sesamum indicum. International Journal. Current Microbiology and Applied Science. 3(6): 486-490. 